\title{
Chile 27F 2010: La catástrofe de la falta de planificación
}

Luis EDUardo Bresciani Lecannelier. Arquitecto P. Universidad Católica de Chile. MAUD Harvard University.

El terremoto y posterior maremoto del $27 \mathrm{de} \mathrm{fe-}$ brero de 2010 en Chile impactó a seis regiones del centro del país, un área donde habita el $80 \%$ de la población nacional. No obstante, la rigurosidad de las normativas chilenas de la construcción redujo considerablemente el número de víctimas fatales, por primera vez en Chile se afecta una gran cantidad de población urbana y un número significativo de ciudades. Este hecho, ha transformado este evento en una catástrofe urbana, que tendrá efectos de largo plazo en la habitabilidad y desarrollo del sistema de centros poblados del centro de Chile. De ahí la importancia del modelo de reconstrucción que el Estado chileno implemente, pues este proceso dejará una huella tan o más profunda que el propio terremoto, afectando los niveles de equidad urbana resultante, los procesos de sostenibilidad institucional, social y económica de muchas ciudades y comunidades.

Según estimaciones de diversos organismos públicos, los daños generados superan las 370.000 viviendas dañadas $1,47 \%$ de las cuales tienen daños mayores o han sido destruidas, lo que se traduciría en más de 250.000 damnificados. A esto se debe agregar la casi total destrucción de los inmuebles con características de patrimonio cultural o urbano, muchos de ellos construidos con técnicas tradicionales en barro, lo que en algunos centros urbanos, como en la ciudad de Talca, ha significado la destrucción de $28 \%$ de las propiedades ${ }^{2}$.
Aunque las infraestructuras de transporte lograron comportarse adecuadamente, los daños también fueron de magnitud, superando los 1.500 millones de dólares. Estos daños han afectado la calidad de vida de miles, la capacidad productiva local de vastas zonas y la operación de las economías asociadas a los mercados externos.

Otro aspecto se asocia a los servicios. Sin considerar el aumento de las demandas que los sistemas de salud y educación han tenido por parte de los damnificados, en materia de servicios básicos el daño ha tenido graves efectos sobre las condiciones básicas de calidad de vida de las personas. 25 hospitales han sido inutilizados y 54 requieren reparaciones ( 4.000 camas de déficit en los hospitales públicos). En materia de equipamientos de educación, cerca de 1.800 escuelas y liceos han sin destruidos o dañados seriamente, afectando a medio millón de niños, y se calcula que más de 4.000 establecimientos públicos y privados de educación ( $40 \%$ del total) tienen daños que requieren reparaciones.

Aunque existen estudios que han cuestionado los costos excesivos planeados por el Gobierno ${ }^{3}$, bajo la sospecha de querer justificar presupuesto para financiar otras prioridades presidenciales, diversos especialistas cuantifican en más de 17 mil millones de dólares los costos de la reconstrucción, siendo más del $47 \%$ de responsabilidad del Estado.

Fuente: Ministerio de Hacienda, Informe del Ministro al Congreso, marzo 2010.

Plan de Reconstrucción de Talca. Polis Consultores, 2010.

Gobierno ha estimado en 30.000 millones de dólares la reconstrucción. 
No obstante, transcurrido los primeros cinco meses desde el terremoto no existe un catastro serio de los daños por ciudad y localidad urbana; las demandas evidentemente son muchas. Sólo en las regiones más afectadas y declaradas como "Zona Afectada por Catástrofe"” , la población supera los 4 millones de habitantes y presenta la mayor dispersión y diversidad de asentamientos urbanos de Chile. Es evidente que cualquier estrategia de reconstrucción urbana seria debiera considerar la existencia de cerca de 900 pueblos de entre 100 a 5.000 habitantes, 45 ciudades con menos de 70.000, 4 capitales con más de 100.000 y el Área Metropolitana de Concepción, de alrededor de 1.000.000 de habitantes. A lo anterior, se debe agregar un alto porcentaje de población rural dispersa que supera el $24 \%$ de la población total de estas regiones. Por eso, debe preocupar que hasta la fecha el gobierno de Chile no tenga un diagnóstico público sobre las prioridades de gasto público por comuna y ciudades.

\section{Dispersión del daño y ausencia del Estado}

Aunque existen casos internacionales exitosos de reconstrucción de ciudades, el volumen, dispersión y diversidad de las comunidades afectadas obliga a tener un enfoque igualmente diverso y capaz de recoger las necesidades y anhelos de cada comunidad, evitando no sólo la estandarización y privatización de las soluciones, sino los perversos efectos territoriales en materia de migraciones y pérdida de empleos que la destrucción genera, especialmente en centros históricos y pequeñas localidades rurales.

Parecía evidente desde un inicio la necesidad de mayor planificación y coordinación de los procesos de reconstrucción, sin embargo, el gobierno ha postergado inexplicablemente el diseño de un "Plan de Reconstrucción Urbana” que establezca con claridad el diagnóstico de los daños, la organización del Estado para abordar las tareas, y los componentes de los planes urbanos necesarios para programar en el tiempo los recursos y acciones públicas.

En lugar de eso, han concentrado los esfuerzos en mecanismos de asistencia individual - como son los subsidios habitacionales a la demanda- y en el fomento a la iniciativa de empresas privadas en el desarrollo de "Planes Maestros Urbanos”, las cuales al ser sólo estudios privados y no contener definiciones públicas sobre formas de participación, prioridades de inversión, costos, programación, financiamiento e implementación, están inevitablemente destinados a ser letra muerta. En algunos casos, como el "Plan Maestro"s de la ciudad de Constitución", la ausencia del Estado en el proceso de planificación ha generado un plan de obras urbanas con costos que superan los 102 millones de dólares ${ }^{7}$. Este plan a pesar de su calidad, por su origen privado no tiene ninguna garantía de ser asumido por el Estado, factor que agudizará aún más las frustraciones de la comunidad. No obstante, el Ministerio de Vivienda y Urbanismo anunció a principios de abril la contratación de 60 Planes de Regeneración Urbana para localidades intermedias y 12 Planes Integrales para grandes centros urbanos, sólo cinco planes se han iniciado, y por su orientación, retrasos y tiempos de elaboración, difícilmente podrán aportar en el mediano plazo a las agendas de reconstrucción y definición de inversiones públicas.

Aprendizajes: más planificación y más Estado El primer aprendizaje de los primeros cinco meses de la emergencia en Chile es que la urgencia sin buenos diagnósticos y planificación pública sólo dilata las soluciones, incrementa los costos directos y de transacción, y reduce la eficacia de la reconstrucción. La improvisación ${ }^{8}$ y las iniciativas privadas descoordina-

4 Regiones de Biobio, Maule y O'Higgins.

5 Plan elaborado por el Consorcio liderado por la Empresa Maderera Arauco y el equipo de arquitectos Elemental.

6 Constitución tiene 40.000 habitantes urbanos.

7 Este monto equivale al $25 \%$ de todo presupuesto anual del MINVU para obras urbanas en todo Chile.

8 Con el fin de expresar urgencia, se han ofertado Planes Urbanos de Reconstrucción elaborados en 90 días, lo que ha llevado a la simplificación y a la falta de evaluaciones.

9 Consiste en la recuperación, en el corto plazo, de los servicios básicos e inicio de las labores de limpieza y reparación del daño de las infraestructuras básicas. 
das, tanto durante la etapa de rehabilitación ${ }^{9}$ como en la etapa de reconstrucción ${ }^{10}$, pueden mostrar hechos de corto plazo, pero atentan a la calidad de la reconstrucción de largo plazo.

Un segundo aprendizaje radica en la necesidad de superar la descoordinación de las acciones públicas, diseñando "Planes de Reconstrucción" que integren las demandas de vivienda, suelo urbano, infraestructuras, equipamientos públicos y regulación. Experiencias nacionales e internacionales han demostrado que las acciones sectoriales dispersas incrementan los plazos de la reconstrucción total, elevan los costos y debilitan la sostenibilidad de largo plazo de las ciudades, reduciendo la efectividad de la inversión y acción pública. Este tipo de planes debieran tomar en cuenta no sólo la eficiente provisión de obras y planes de ordenamiento territorial, sino también los mecanismos que garanticen procesos descentralizados, participativos y equitativos en la distribución de los recursos públicos y beneficios privados. A diferencia de lo ocurrido en otras catástrofes históricas en Chile, el gobierno no ha planteado aún la necesidad de perfeccionar los mecanismos de planificación, financiamiento e institucionalidad urbana que se requieren para enfrentar este tipo de eventos.

Un tercer aprendizaje es que la reconstrucción requiere de autoridades descentralizadas e instancias permanentes de participación local ${ }^{11}$. Ejemplos como el de Nueva Orleans después del huracán Katrina muestran los perjuicios de la superposición de responsabilidades entre autoridades locales, regionales y nacionales. Por la magnitud y diversidad de la reconstrucción, la gestión centralizada de la reconstrucción atenta contra la efectividad y validez de los planes de reconstrucción. La debilidad y ausencia de autoridades locales o gerencias a cargo del proceso de reconstrucción y de mecanismos de validación social de las intervenciones públicas, se traducirá en la descoordinación entre acciones del Estado, en planes carentes de identidad local y viabilidad, y en la destrucción del ya debilitado tejido social.

Un cuarto aprendizaje es la urgencia de establecer a priori los criterios de asignación de recursos públicos, a fin de garantizar equidad, progresividad y transparencia en la distribución de los fondos públicos entre las regiones y comunas afectadas. Sin la adecuada programación del gasto público disponible por ciudad y comuna (ley de presupuesto de la nación), no sólo se incentivan las expectativas de la gente y la creación de planes urbanos inviables, sino que se posterga en años el inicio de las obras. En el caso de esta catástrofe, la falta de diagnósticos impedirá que se puedan programar recursos públicos para el 2011, lo que implica que las primeras obras de recuperación urbana se iniciarías a lo menos en dos a tres años más.

Finalmente, una quinta y última lección radica en la necesidad de una visión compartida y nacional sobre la reconstrucción entre todos los actores politicos y sociales. Tal como ocurrió en otros casos internacionales, la falta de objetivos compartidos y la débil voluntad del gobierno central por llegar a acuerdos nacionales en la materia, augura un escenario de permanente beligerancia entre actores políticos y sociales. Esto atentará contra los resultados esperados de todo buen proceso de reconstrucción, como son mejorar la calidad de vida de las personas, elevar los niveles de equidad social y construir un Estado más eficiente y democrático.

Un país que no aprende y sale fortalecido de una catástrofe, volverá a exponer a sus habitantes a la fragilidad y la incertidumbre, debilitando las bases mismas de la democracia y el desarrollo. IEURE

10 Consiste en la reparación y/o reemplazo, a mediano y largo plazo, de la infraestructuras y edificaciones dañadas, y en la restauración y/o perfeccionamiento de los sistemas de producción (DS 156 de 2002, Plan Nacional de Protección Civil).

11 La creación de consejos locales ad hoc para la reconstrucción, presididos por los alcaldes y con participación de representantes de la comunidad, es un mecanismo facultado legalmente (Ley 16.282 Art. $3^{\circ}$ letra a). 